\title{
Design of an Experimental Injection Moulding Tool for Testing Microstructured Cavity Surfaces
}

\author{
Krisztián KUN \\ John von Neumann University, GAMF Faculty of Mechanical Engineering and IT, Department of Innova- \\ tive Vehicles and Materials, Kecskemét, Hungary, kun.krisztian@gamf.uni-neumann.hu
}

\begin{abstract}
This research is based on the impact assessment of the active element of injection moulding tools. The quality of the tool surface has a significant effect on the filling and cooling efficiency. Our goal is to create a uniform structure on the cavity's surface that results in a high degree of orientation during the injection moulding process. A special experimental tool is needed for the research. Our design was based on the results of previous experimental research and preliminary criteria. The design was based on the size and position tolerances of the A side of the tool. As the previous study has shown, there are three main points to consider when designing an experimental moulding tool. These are the applied manufacturing technology, Design for Assembly, and the expansion of the measurement possibilities by using different sensors. The small beam size of the femtosecond laser also allows the machining of microscopic-sized details, a technology used to structure the cavity surface. The success of this was analyzed by microscopic examination.
\end{abstract}

Keywords: surface structure, femtosecond laser, injection moulding, surface mapping, insert.

\section{Introduction}

During the injection moulding process, there is always some degree of molecular orientation that differs in the cross section of the product. In the case of an isothermal flow of polymer melt, the velocity of the layers next to the wall will be lower than in the middle of the channel due to friction. In the flow of long-molecular materials, they must not be perpendicular to the flow direction, but the macromolecule must be oriented parallel to the melt flow. The degree of orientation next to the wall is higher than in the middle of the channel because of the velocity profile. Moving towards the middle of the product, we find less oriented layers. This complex process shows that several layers with different orientations are formed in polymer products. These zones are temporary, there is no sharp separation between them. Since the quality of the tool surface has a significant effect on the filling and cooling efficiency, it can be assumed that the ratio of the layers with different orientations change, thus also changing the mechanical properties of the polymer products.
A special experimental injection moulding tool was designed to investigate the mechanical properties [1, 2].

\subsection{Introducing the previous experimental injection moulding tool}

The experiment was aimed at examining the active elements, so the design was based on the size and position tolerances of the A plate. We wanted to create two different geometries that cause a large scale orientation during the injection moulding process. Perpendicular and parallel groove geometries (to the flow direction) were formed on both sides of the cavity's surface. The designed depth of the grooves were $100 \mu \mathrm{m}$ (Figure 1) $[3,4,7]$.

\subsubsection{Selecting the production method}

AAs an applied manufacturing technology, we chose milling to create the structures. The cutting was performed with a $30^{\circ}$ tip carbide engraving tool with a $0,2 \mathrm{~mm}$ edge rounding and a TiN coating. During engraving, the tool suffered increased wear due to the length of the tracks. Type: SKU311611 (Figure 2) [3-5]. 


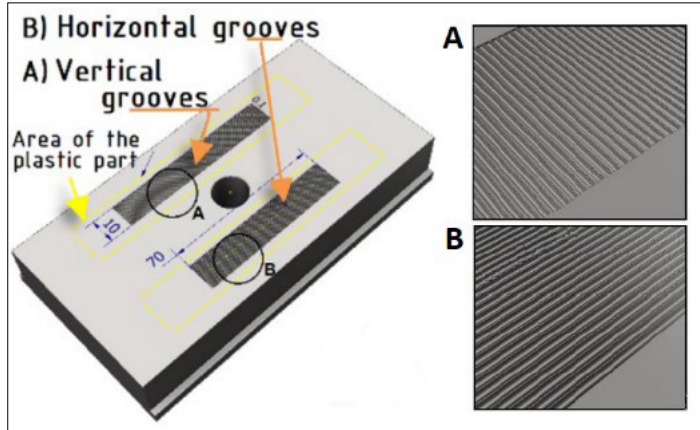

Figure 1. CAD model of the cavity with the created surface structure. [3]

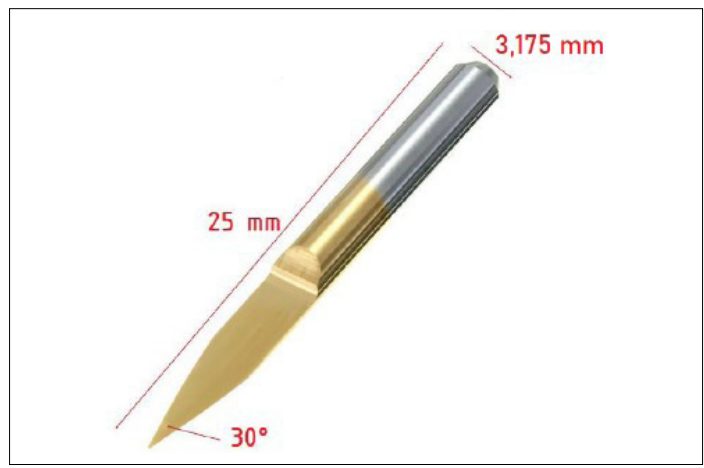

Figure 2. TiN coated, carbide engrave tool. [3]

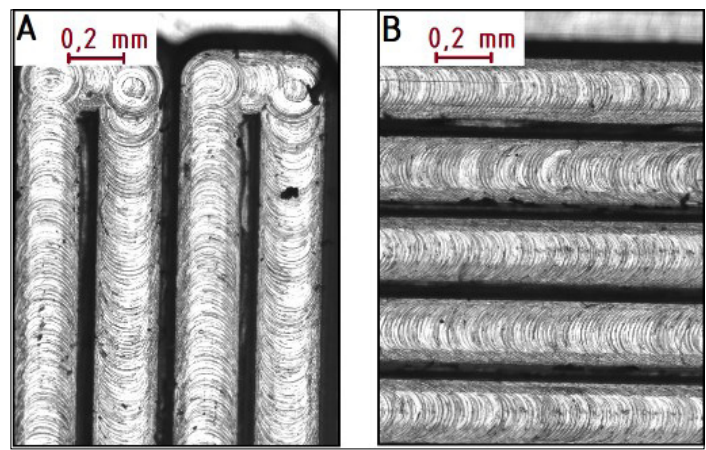

Figure 3. The vertical $(A)$ and the horizontal (B) grooves recorded with digital microscope. [3]

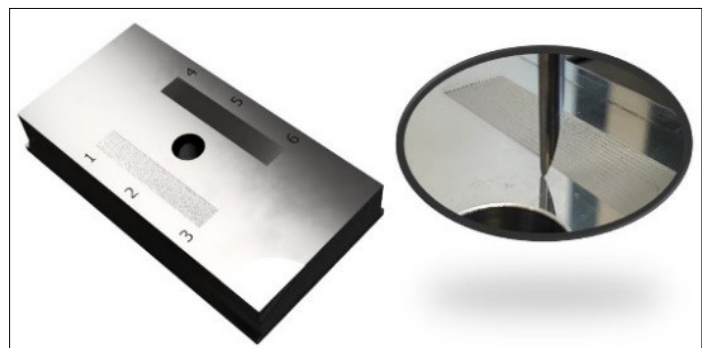

Figure 4. The marked measuring sections on the insert, used for contour measurement [3]

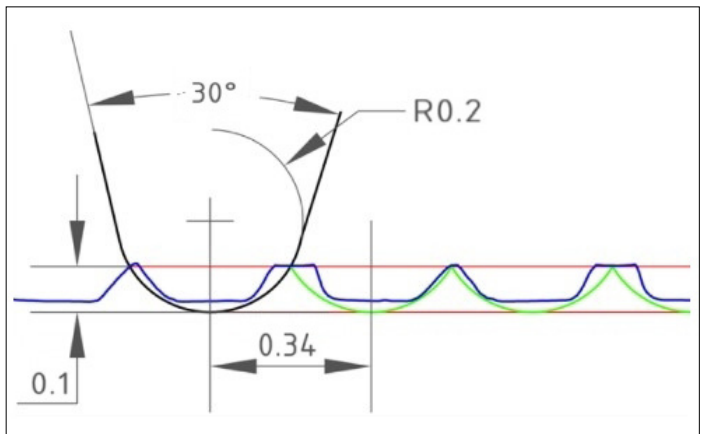

Figure 5. Measured geometries on the insert's surface: green is the designed, blue is the formed contour. [3]

\subsubsection{Results after the machining process}

After recording the geometric boundary conditions, the designed grooves were analyzed with a Mitutoyo QuickVision Elf Pro digital microscope.

The macro- and micro-geometrical characteristics of the formed grooves can be clearly seen on the images, like the width of the structures, or its roughness (Figure 3) [3, 4, 6].

\subsubsection{Examination of geometries on the in- sert's surface with a contour measuring device}

AThe parallel and perpendicular trajectories were divided into 3-3 sections for contour measurement at a length of $3.5 \mathrm{~mm}$. The sections were marked at the beginning, middle and end of the track. This method made it possible to detect height differences due to tool wear (Figure 4).

The difference between the engraved tracks was already visible in the microscopic images, and was also confirmed by the contour measurement. The grooves created by engraving showed a regular arrangement in terms of their geometry, whereas the contours of the parallel and perpendicular profiles did not show significant differences. The average value of tool wear was $0.02 \mathrm{~mm}$. It can be clearly seen in Figure 5 that the distance of the toolpaths approaches the programmed value $(0.34 \mathrm{~mm})[3,4,8]$.

\subsubsection{Summary of experiment}

To show greater consistency for the designed sur-face elements, careful technological and geometric predesign is required. This was well illustrated by the results of the contour measurements. From a technological point of view, the engraving must be replaced by a process that can create a unified texture everywhere. In addition, the aim is to create a structured tool insert which 
can be fixed to the mould cavity via mountable inserts to provide the exchange of different surface topographies and examining their effects. Another goal is to be able to monitor the diagnosis of process parameters with temperature and pressure sensors during production.

\section{Design of an experimental injection moulding tool}

\subsection{Factors affecting the design}

As the previous study has shown, there are three main points to consider when designing the experimental injection moulding tool. The applied production technology, the easy-to-install design and the measurement possibilities by using various sensors.

\subsubsection{Machining with femtosecond laser}

A common feature of laser beam material processing technologies is that the material separation forms a constant and unified surface. The small beam size of the femtosecond laser also makes it possible to process details of microscopic size and generates short pulses that don't make thermal marks on the machined part (Figure 6). During laser ablation, the material goes through an erosion process. In the present research, our goal is to create a uniform surface that contains grooves of the same depth everywhere. During production, we have to deal with potential problems such as the avoidance of plasma formation and oxidation, and the minimization of the size of the heat affected zone (HAZ). [9, 10].

The laser machine which was available to us is a Monaco 1035-80-40 type industrial femtosecond laser (Figure 7), equipped with a LINOS F-Theta-Ronar type scanner optics. The laser is capable of delivering $80 \mu \mathrm{J} /$ pulse energy at a wavelength of 1035 nanometers. The maximum adjustable pulse width is $277 \mathrm{fs}$ [F].

The exact technical characteristics of the laser machine used are given in Table 1.

\subsubsection{Design of the structured tool inserts}

In the new experimental tool, the structured inserts are located in the moving side of tool (Figure 8). The inserts are fixed by two additional grinded inserts which are screwed to the tool body. The product of the tool is two standard polymer tensile test specimens that can be used for mechanical tests.

In previous research, we created two samples with different orientations. Thanks to laser tech-
Table 1. The technical parameters of the Monaco 103580-40 type femtosecond laser [11]

\begin{tabular}{|l|c|}
\hline Average performance & $40 \mathrm{~W}$ \\
\hline Energy & $80 \mu \mathrm{J}(500 \mathrm{kHz}-\mathrm{en})$ \\
\hline Frequency range & $188 \mathrm{kHz}-50 \mathrm{MHz}$ \\
\hline Wavelength & $1035 \pm 5 \mathrm{~nm}$ \\
\hline Pulse width & $<350 \mathrm{fs}$ \\
\hline Mode & TEM00, M2 <1,2 \\
\hline
\end{tabular}

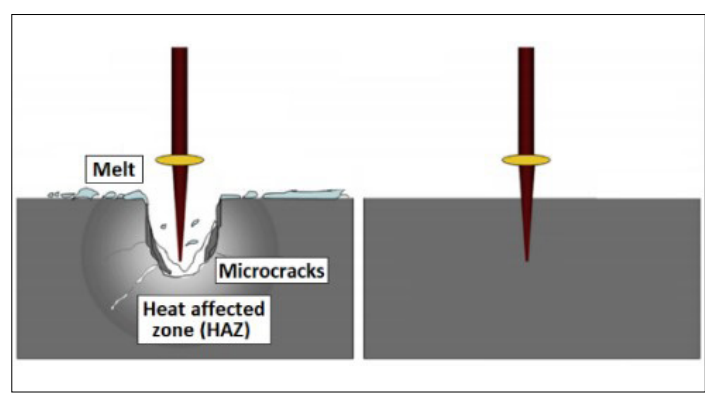

Figure 6. Long pulse (left) and short pulse lasers (right) heat affected zone. [13]

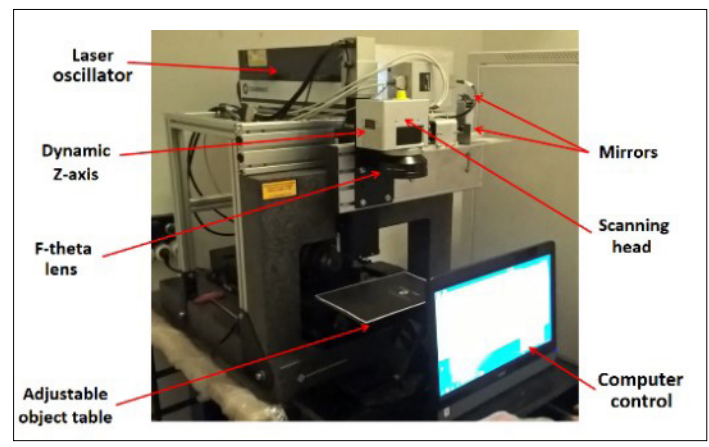

Figure 7. Parts of the femtosecond laser machine.

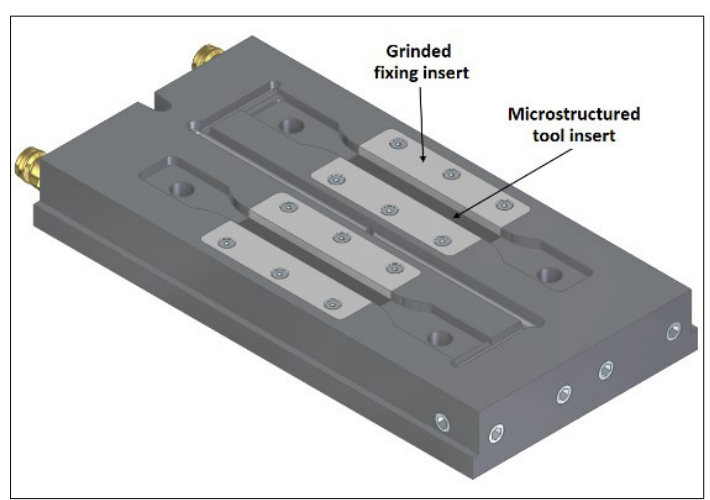

Figure 8. CAD model of the experimental injection moulding tool 
nology, various microstructures can be reproduced with good repeatability. The base of the insert is a grinded M200 tool steel with $\mathrm{R}_{\mathrm{a}}=0.4 \mu \mathrm{m}$ roughness. In addition to the parallel and perpendicular samples, the further aim is to create various raster samples.

The advantage of the designed tool is that the inserts of different orientations can be exchanged on both sides of the plate. For the comparative analyzes of the mechanical tests, grinded surface insert with $\mathrm{R}_{\mathrm{a}}=0,4 \mu \mathrm{m}$ roughness is also manufactured. The useful structurable surface of the inserts is $78 \times 10 \mathrm{~mm}$ (Figure 9).

\subsubsection{Sensors}

There are two ways to install an electro-resistive pressure sensor: direct and indirect method. In the case of the direct method, the sensor can be tightly fitted directly to the mould cavity. The continuous prestressing, maintenance and installation affect the measurement accuracy. In the indirect installation used for the experimental tool, an inverted pin is inserted behind the ejector pin with a loose fit, thus transmitting the force from the pressure. It has the advantage of being stressfree and maintenance-free throughout the life of the tool. For more exact test results, it is recommended to use additional sensors to measure the melt temperature [12].

\section{Results}

Following the design, the manufactured inserts were surface treated with a femtosecond laser and the result was examined with a Mitutoyo QuickVision Elf Pro digital microscope. The designed dimensions of the grooves are illustrated in Figure 10.

There may be several reasons for the "V" profile geometry (Figure 11):

The beam source of the laser beam is in TEM00 mode, therefore the intensity distribution of the beam follows a Gaussian-distribution. In our case, the intensity is highest in the middle of the beam, gradually decreasing outward, as shown in Figure 12.

In order to create the planned depth, the structures were made by multiple scans. During dynamic focus control, the machine first focused on the surface, resulting a $60 \mu \mathrm{m}$ wide channel. After the focus shift, the channel width $(60 \mu \mathrm{m})$ would still have been made constant, but due to the divergence of the beam, the ablation limit was also reached in the positive direction from the focus position, which further widened the chan-

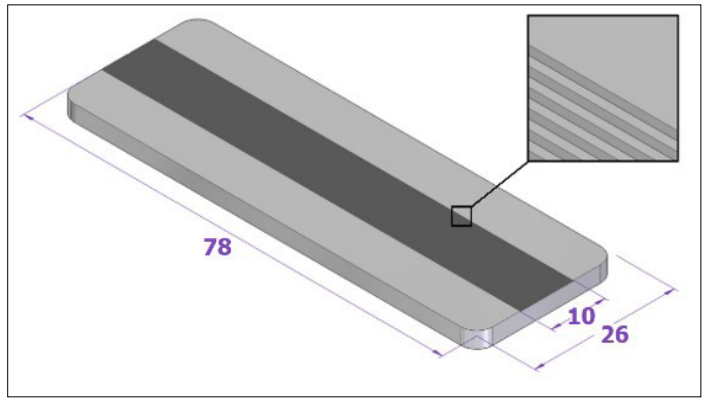

Figure 9. Tool insert with horizontal grooves.

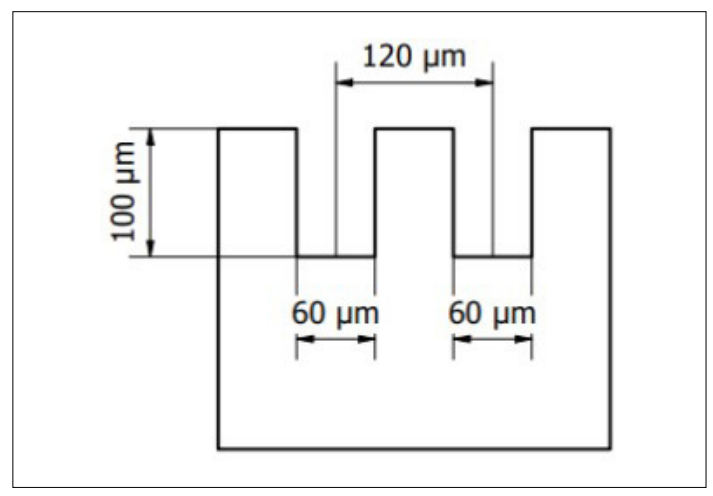

Figure 10. The designed dimensions of the cavity's surface.

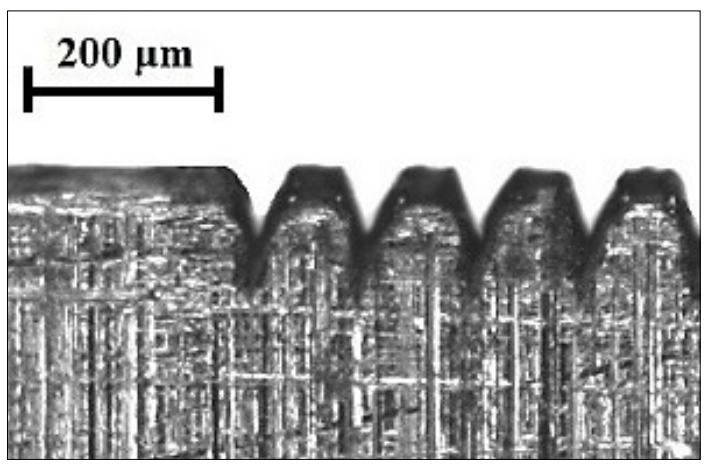

Figure 11. Microscopic image of the surface structure.

nel. Scattered radiation within the channel can remove additional material from layers closer to the surface due to multiple scans.

\section{Conclusions}

In the case of a polymer melt flow, the macromolecules cannot be arranged perpendicular to the flow direction. This results in a parallel orientation to the direction of the melt flow. Due to friction, the speed of the layers next to the wall 


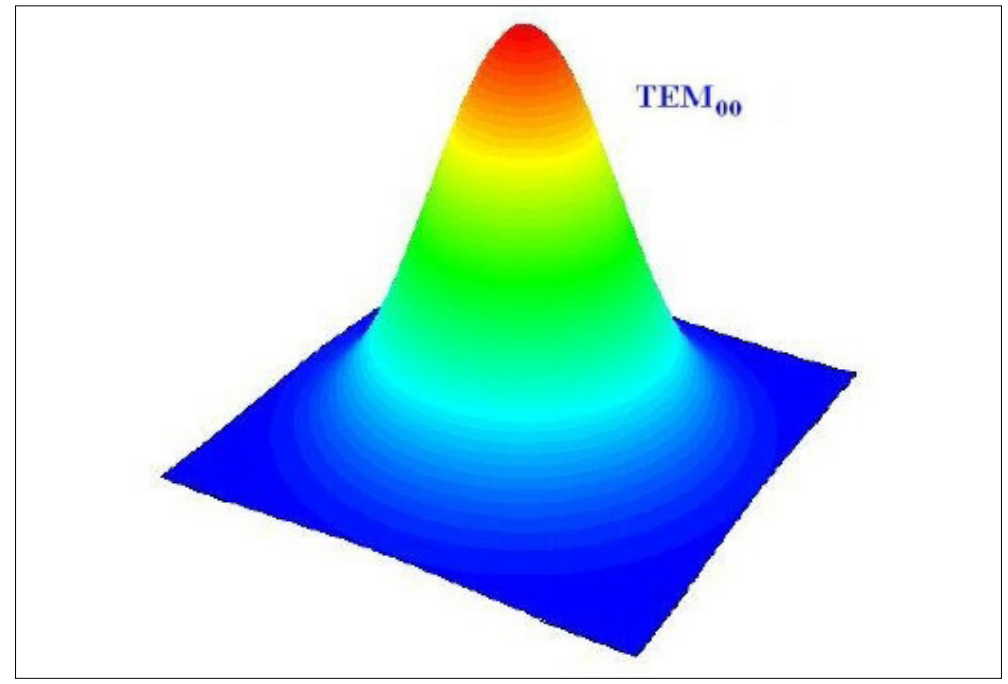

Figure 12. Gaussian-beam of the Monaco 1035-80-40 femtosecond laser [11]

is lower. It follows from the velocity profile that the degree of orientation next to the wall is higher. Moving towards the middle of the product, the orientation decreases. Based on previous research, the surface quality of the forming surface of the tool during injection moulding has an effect on the filling and cooling efficiency. This phenomenon can modify the ratio of layers with different orientations, changing the mechanical properties of injection moulding products.

As a result of the present research, a special experimental injection moulding tool was designed to influence the molecular orientation during the injection moulding process. With its help, the results of the preliminary studies can be validated, the research area can be further expanded. The applied femtosecond laser technology can be used to create a uniform surface structure.

\section{Acknowledgement}

This research is supported by EFOP-3.6.1-16-201600006 "The development and enhancement of the research potential at Pallas Athena University” project. The Project is supported by the Hungarian Government and co-financed by the European Social Fund.

\section{References}

[1] Pantani R., Sorrentino A., Speranza V., Titomanlio G.: Molecular orientation in injection molding: experiments and analysis. Rheologica acta, 43/2. (2004) 109-118.

https://doi.org/10.1007/s00397-003-0325-8

[2] Pósa M., Belina K., Boza P.: Amorf és kristályos polimerek mechanikai tulajdonságainak vizsgálata. Inter-Ing, Târgu Mureș, 2006. 69-72.
[3] Kun K., Boza P., Weltsch Z.: Polimer ömledék leképeződésének vizsgálata formaüreg felületi struktúráin. Gradus, 6/1. (2019) 192-198.

[4] Kun K., Boza P.: Investigation of inserts surface structures on injection moulded parts. In IOP Conference Series: Materials Science and Engineering, 448/1. (2018) 012052.

https://doi.org/10.1088/1757-899X/448/1/012052

[5] Fleischer J., Kotschenreuther J.: The manufacturing of micro molds by conventional and energyassisted processes. The International Journal of Advanced Manufacturing Technology, 33/1-2. (2007) 75-85. https://doi.org/10.1007\%2Fs00170-006-0596-1

[6] Holthusen A. K., Riemer O., Schmütz J., Meier A.: Mold machining and injection molding of diffractive microstructures. Journal of Manufacturing Processes, 26. (2017) 290-294. https://doi.org/10.1016/j.jmapro.2017.02.014

[7] Theilade U. A., Hansen H. N.: Surface microstructure replication in injection molding. The International Journal of Advanced Manufacturing Technology, 33/1. (2007) 157-166. https://doi.org/10.1007/s00170-006-0732-y

[8] Pósa M., Belina K., Boza P., Szűcs A.: Examination of the effect of machining technology on the surface of injection moulding parts. Inter-Ing, TârguMureș, 2005, 19-25.

[9] Temmler A., Willenborg E., Wissenbach K.: Design surfaces by laser remelting. Physics Procedia, 12. (2011) 419-430. https://doi.org/10.1016/j.phpro.2011.03.053

[10] Preußner J., Oeser S., Pfeiffer W., Temmler A., Willenborg E.: Microstructure and residual stresses of laser structured surfaces. In Advanced Materials Research, 996. (2014) 568-573. 
https://doi.org/10.4028/www.scientific.net/ AMR.996.568

[11] Monaco: Industrial Femtosecond Laser adatlap https://dokumen.tips/documents/monaco-1035-edge-1035-industrial-femtosecond-laser-monaco-1035-is-an-industrial.html (accessed on 2021. 02.15.)
[12] Cavity Eye: Szerszámnyomás mérés http://cavityeye.com/froccsontes-technologia (accessed on: 2021. 02. 15.)

[13] Gergely J. : Átlátszó PMMA megmunkálása femtoszekundumos lézerrel. Gradus, 8/1. (2021) 219226.

https://doi.org/10.47833/2021.1.ENG.001 